Article

\title{
A Bayesian Network Based Adaptability Design of Product Structures for Function Evolution
}

\author{
Shaobo $\mathrm{Li}^{1,2}$, Yongming $\mathrm{Wu}^{1,2, *}$, Yanxia $\mathrm{Xu}{ }^{1}$, Jie $\mathrm{Hu}{ }^{1,3}$ and Jianjun $\mathrm{Hu}^{2,3, *}$ (i) \\ 1 Key Laboratory of Advanced Manufacturing Technology (Guizhou University), Ministry of Education, \\ Guiyang 550025, China; lishaobo@gzu.edu.cn (S.L.); kmlg2010@163.com (Y.X.); jason.houu@gmail.com (J.H.) \\ 2 School of Mechanical Engineering, Guizhou University, Guiyang 550025, China \\ 3 Department of Computer Science and Engineering, University of South Carolina, Columbia, SC 29208, USA \\ * Correspondence: ymwu@gzu.edu.cn (Y.W.); jianjunh@cse.sc.edu (J.J.H.)
}

Received: 5 February 2018; Accepted: 22 March 2018; Published: 26 March 2018

check for updates

Featured Application: The designers and managers for product development in a production enterprise (e.g., the production of electric toothbrush) can obtain an optimal solution for structure dynamic design through the evolution design model based on Bayesian network proposed in this paper.

\begin{abstract}
Structure adaptability design is critical for function evolution in product families, in which many structural and functional design factors are intertwined together with manufacturing cost, customer satisfaction, and final market sales. How to achieve a delicate balance among all of these factors to maximize the market performance of the product is too complicated to address based on traditional domain experts' knowledge or some ad hoc heuristics. Here, we propose a quantitative product evolution design model that is based on Bayesian networks to model the dynamic relationship between customer needs and product structure design. In our model, all of the structural or functional features along with customer satisfaction, manufacturing cost, sale price, market sales, and indirect factors are modeled as random variables denoted as nodes in the Bayesian networks. The structure of the Bayesian model is then determined based on the historical data, which captures the dynamic sophisticated relationship of customer demands of a product, structural design, and market performance. Application of our approach to an electric toothbrush product family evolution design problem shows that our model allows for designers to interrogate with the model and obtain theoretical and decision support for dynamic product feature design process.
\end{abstract}

Keywords: product function evolution; data analysis; Bayesian network; adaptability design

\section{Introduction}

The availability of big data is changing the business practice in many industries, such as manufacturing, which is increasingly facing the challenge of market demand for customized feature-rich products and high costs it may bring. The data collected during the whole lifecycle of products make it possible to develop a data-driven product design and evolution model to identify the pros and cons of different design/structural or function features, and how these options affect the customer satisfaction and final market sales. Here, "big data" refers to the fact that now we are using the data from the whole lifecycle of the product family for product design as compared to previous practice of using data from a single product. Recently, an increasing number of studies have been conducted to find the way that can collect, process, and analyze the large and diverse product data quickly and effectively $[1,2]$. As such, studies on the data driven product family function evolution 
and structure dynamic design are of great significance to improve efficiency and reduce cost in the product manufacturing process and related technologies [3].

This paper is concerned with a major problem in the product family design in manufacturing enterprises. For example, an electric toothbrush manufacturer makes different types of models, all with different functional or structural features. A lot of contradictory design decisions and related technologies [4-6] have to be made: adding more features usually increases customer user experience and thus customer satisfaction. However, more features usually mean higher manufacturing costs and higher sale prices, which may end up leading to less sales. Another example is adding self-cleaning feature to electric toothbrushes can reduce cleaning time, but add weights to the toothbrushes. How to reach a good balance among all these design decisions and customer satisfaction and then maximize the sales is a major design problem in such enterprises. Traditional ad hoc expert knowledge based method is far from being satisfactory. Here, we are proposing a data-driven Bayesian model to understand the principles of dynamic product evolution design processes.

Product Family (PF) strategy [7] differs from single product development in that it aims to maximize the overall performance by adjusting the balance between performance and commonality within products that have some similar characteristics (a product family). Recently, there are many studies that are related to PF [8-11]. Therein, regarding to PF design, Jiao et al. [12] divided the developing approaches into two classes, i.e., modularized and parameterized. As to the former, the interchangeability and composability of the modular is the foundation of PF design. In the relevant studies, Zhang et al. [13] established the product development platform via modular modeling and completed the modular and serialization design, on the basis of the distinction of basic modularity, required modularity and optional modularity [14]. Alsawalqah et al. [15] proposed a design method for product platform based on the matrix design, according to the axiomatic design theory and the analysis on functional requirements. On the other hand, with regard to the parameterized PF, a hybrid co-evolution optimal design method is presented by Schuh et al. $[16,17]$ with the aim to ensure the balance of platform commonality and performance in PF design.

On product family evolution research, data-driven PF is upgraded, extended, updated, and replaced with the time change [18], namely PF evolution problem. The market driven PF design method is proposed to deal with the influence of market segment [19]. Negendahl et al. [20,21] firstly studied the modular theory and the implementation for PF core system and proposed a dynamic planning method for the PF modular. Moreover, they established a model that is based on the Bayesian network to analyze the evolution of core modules in PF design [22]. The evolution process of PF involves two aspects: macro and micro, and the design strategies of the product includes evolution design, expansion design, and upgrade design. In order to understand the upgrade and derivation of the platform, Meyer presented the methods of evolution platform and R\&D performance management [23]. Wang [24] put forward the development and management strategy of product platform, based on the theory of life cycle of product platform.

In summary, PF development strategy can bring competitive advantage in new product development. Although existing studies may be playing important roles in product design, most of the studies are limited to traditional design approaches and are based on designer's experience. In other words, product structure designs based only on functionality rather than the entire design-manufacturing-sale process. Especially, there is a lack of quantitative data analysis in function evolution and the product structure dynamic design. Most of product evolution design methodologies focus on function $[25,26]$ and structure mapping during the product design process without considering the dynamic relationship between product function and structure.

The main contributions of this paper are:

(1) We propose a Bayesian network based model for product dynamic design reasoning. It has the advantage of crossing the barrier of traditional product design methods and empirical experience. This model allows for us to represent all of the relevant factors and their dependency relationships in a probabilistic way so that a variety of inferences can be conducted to guide the design process. 
(2) We develop a product dynamic design scheme using data analysis and reasoning. Since product design is not only related to changes in customer demands, but also other factors in the implementation process with direct or indirect relationships, it is difficult to analyze the complex rules that are hidden in the product design process. Our method provides a quantitative way to learn these design rules.

(3) We establish a probabilistic product dynamic design model to model the uncertainty that is involved in market demand and the structural diversity of products.

(4) We obtain product dynamic evolution law through Bayesian network model based reasoning, which provides the theoretical basis for product evolution (dynamic) design.

The overall structure of this paper is as follows. Section 2 describes how the available data from lifecycle of products enables us to develop a data driving model for exploring the product design evolution. In Section 3, we propose the Bayesian Network based dynamic design model, including its structure determination and parameter learning. We then apply the proposed model to study the product design evolution process of electronic toothbrushes in Section 4. Finally, we draw conclusions about our works in Section 5.

\section{Function Evolution in PF Design}

\subsection{Data Driven PF Dynamic Design}

Data analysis is widely used in product design, manufacturing, specialty industries, and other industrial fields [27]. The related data in manufacturing area provides companies with information support for the whole product life circle including R\&D, production, sales, services, and so on. In the field of product design and manufacturing, it becomes increasingly an important research problem to develop approaches for collecting, processing, and analyzing the large and diverse data to be used in the so-call data driven product design. This will allow for manufacturing enterprises to enhance their business model, to build the manufacturing system model with corresponding algorithms so that they can better respond to the market changes in a quick and flexible way. The main goal is to achieve the optimal allocation of manufacturing system resources, in which data driven product dynamic design has big potential to enhance the competitiveness of manufacturing enterprises to achieve maximum performance. The Figure 1 shows the elements and structure of Data-driven product evolution design reasoning system. In this system, market needs, manufacturing techniques, and all related factors are first modeled based on their declarative representations. Then, the data from the product lifecycle and the domain expert knowledge are combined with the elements to build the data-driven product evolution design reasoning system, which allows for us to interrogate with the model to figure out how to adapt the product design based on the changes of market demands.

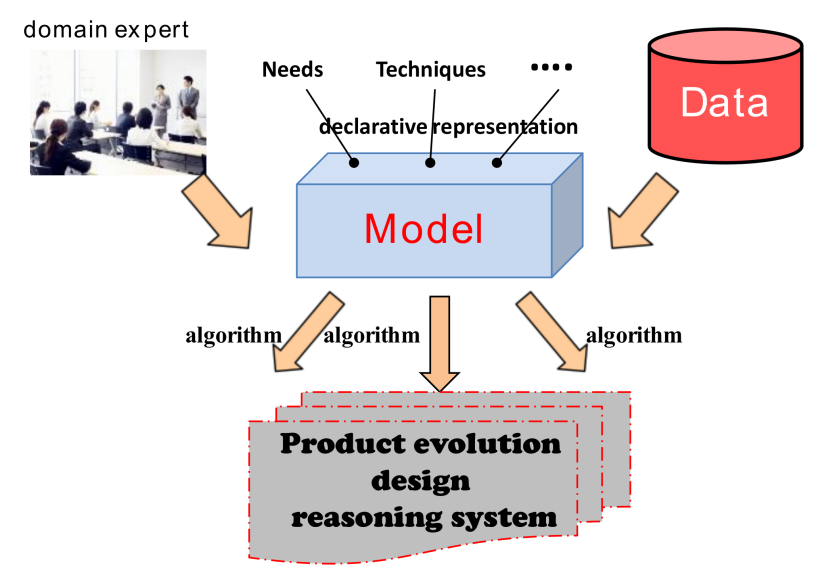

Figure 1. Data-driven product evolution design reasoning system. 


\subsection{Evolution Design Analysis for PF}

It is well known that contradictions always exist in the whole process of product design and manufacturing. Therefore, the essence of the evolution design of PF is to seek the balance for all kinds of contradictions to achieve the optimal overall performance of the enterprise. Indeed, in the initial stage, the purpose of product function and structure design is to meet the market needs and to achieve the initial balance of the contradictions. However, due to some unexpected changes of the external factors in the manufacturing process of $\mathrm{PF}$, the initial balance is broken, which demands the product functions to be extended, upgraded or even re-designed to keep up with the market needs again. Consequently, the relation of product requirements and the functional structures often exhibits as a dynamic balancing process over the time, as shown in Figure 2. For example, as time goes on, similar products that are in the same product family may reveal a decline in the performance and individual difference. At this time, a dynamic optimization is needed to be conducted in the manufacturing process of PF to achieve the optimal overall performance.

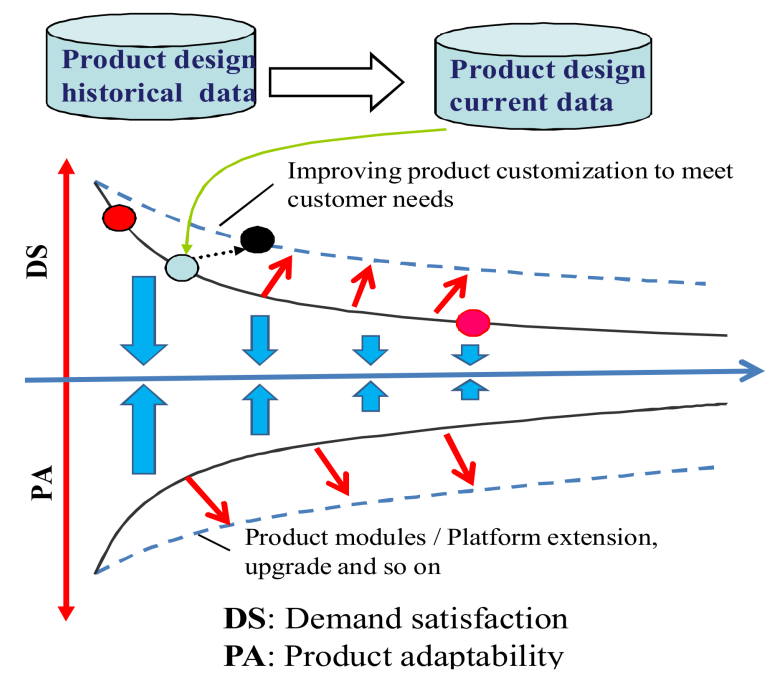

Figure 2. Dynamic balancing processof market demand and product adaptation over time.

To achieve optimal dynamic balancing of market demand and product adaptation, we propose a Bayesian Network based reasoning model using the data collected from the implementation of the existing PF, by analyzing the correlation of the market needs and the design elements. We express the product requirements via data analysis and dynamic design of function and structure. This model allows for us to take customer needs as the evidence of the Bayesian network reasoning model to extract the evolution rules of product design and manufacturing. After that, the dynamic adaptive design of PF is conducted through analyzing the effect of product requirements and technology on the product design planning.

\section{Data-Driven Dynamic Design Model for Product Structure}

The basic idea of our dynamic design model for product structures is to decompose a product design into different structural or function features, each with several options. These will lead to a large number of feature combinations, which can cause different costs, sale prices, customer satisfaction, and final amount of sales. Our idea is to model each of the design decisions/features as well as the customer and market responses as random variables and use historical data to learn the structure of a Bayesian network, which reflects the dependency relationships of the variables. 


\subsection{Probablistic Reasoning and Analysis Based on Bayesian Network}

A Bayesian Network, also known as belief network, is a graphical model, which can not only describe the dependency among data variables but also be used for reasoning [28]. It is commonly adopted to deal with uncertainty reasoning problems by providing a convenient framework to express the causal relationships and to make the uncertainty derivation clear in logic [29,30]. As dynamic product design models involve many factors that have probabilistic relationships, Bayesian Networks can be used to describe and analyze the relations among the properties of the core modules of products in PF with strong readability and ease for reasoning.

Typical Bayesian Networks are usually composed of the nodes that represent the variables and directional connections among the nodes. The detailed description is shown as follows:

Let Set $X=\left\{X_{1}, X_{2}, \ldots, X_{n}\right\}$, in which the definition domain of a random $X_{i}$ is a finite set $\operatorname{Val}\left(X_{i}\right)$. $N=\langle G, P>$ represents an established Bayesian Network based on $X$, where $G$ is a directed acyclic graph, of which the values of the nodes are the random variables $X_{1}, X_{2}, \ldots, X_{n}$ of $X$ and the directional connections stand for the causal relationships. $P$ represents conditional probabilities of the nodes in $G$, for an arbitrary node $X_{i}, P\left(X_{i} \mid P a\left(X_{i}\right), X_{i} \in X\right)$ reflects the conditional probability of $X_{i}$ on the occurrence of its parent $P a\left(X_{i}\right)$. In this scenario, the distribution of the network can be expressed as follows [31].

$$
P\left(X_{1}, X_{2} \ldots, X_{n}\right)=\prod_{i=1}^{n} P\left(X_{i} \mid P a\left(X_{i}\right)\right)
$$

According to the above description, the characteristics of the Bayesian Network can be summarized as:

$>$ the conditional independence and dependency among the attributes is intuitivein the Bayesian Network; and,

$>$ the Bayesian Network depicts the joint probability distributions of events in a more succinct form. Therefore, the occurrence probability of a given event can be derived rapidly according to the structure of the network and the probability table.

\subsection{Dynamic Design Model Based on Bayesian Network}

\subsubsection{Structure of the Network Model}

In this study, in order to represent the dynamic evolution rules of product structure design, product requirements and design elements are first abstracted into nodes of the Bayesian network. Moreover, the structure of the Bayesian network model is determined by means of data training and domain expert modification. Firstly, the network structure is trained based on the historical data and network structure learning, which has been proved to be a NP-hard problem to date. The commonly used learning algorithms include $K 2$ (used in this paper), TANC, GS, HC, and so on [32]. Usually, the network measures the dependency relationships between nodes via mutual information. If the value of the mutual information is larger than a certain threshold, then there should be an edge between the nodes in the network. The calculation of the mutual information $I\left(X_{1}, X_{2}\right)$ between two random nodes $X_{1}, X_{2}$ can be represented as follows.

$$
I\left(X_{1}, X_{2}\right)=\sum_{X_{1} X_{2}} P\left(X_{1}, X_{2}\right) \log \frac{P\left(X_{1}\right) P\left(X_{2}\right)}{P\left(X_{1}, X_{2}\right)}
$$

The structure learning of a Bayesian network is to find a Directed Acyclic Graph (DAG) to explain the data set in the best way under the circumstance of data completeness. The principle is shown below.

The training dataset is denoted as $D$ and the hypothesis of the network structure is denoted as $S^{h}$. Thus, the process of finding out the best structure for data set $D$ is essentially locating the maximum value of $P\left(S^{h} \mid D\right)$. According to Bayesian theory, the calculation can be denoted as follows: 


$$
P\left(S^{h} \mid D\right)=\frac{P\left(S^{h}, D\right)}{P(D)}=\frac{P\left(D \mid S^{h}\right) P\left(S^{h}\right)}{P(D)}
$$

where $P(D)$ is a constant that has nothing to do with the network. $P\left(D \mid S^{h}\right)$ represents the boundary likelihood of the network. $P\left(S^{h}\right)$ is also a constant that represents the prior probability of the network. Consequently, determining the posterior distribution of the network structure is equivalent to the calculation of the data process hypothesis for every potential structure.

In order to ensure the established network structure can not only be objectivity learned but also reflect the special regularities of the dynamic evolution of product structure, we need to consider factors such as improvement of market demand, the progress of technology as well as the external environment, which all have an impact on the product structure design.

What is more, the prior knowledge of the experts in the product design domain should be fully considered in learning the Bayesian Network structure, including dependency and probability of the nodes, leading to a network structure suitable for network reasoning and the interrogation of the learned model. A typical network analysis model is revealed in Figure 3, which can be used to calculate the joint probabilities of a variety of events given the parametric network model.

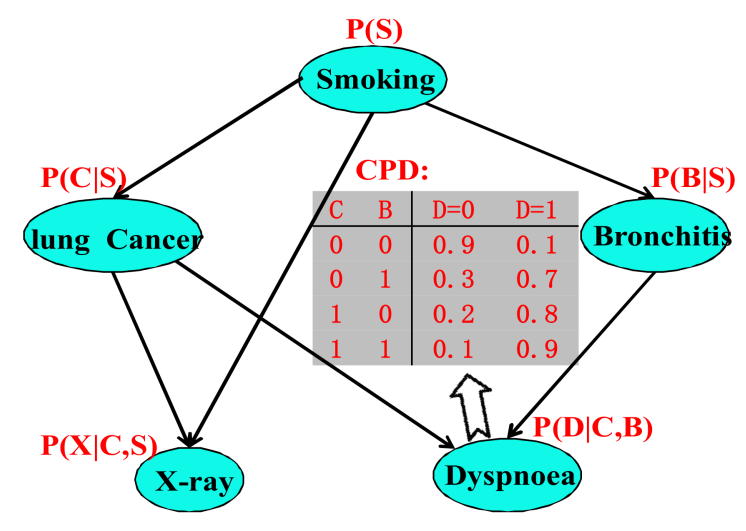

Figure 3. Analysis model based on Bayesian network.

\subsubsection{Parameters Learning of the Bayesian Network}

For a given dataset $D$ and topological structure $S^{h}$, the probability density of the network node variable can be determined by using prior knowledge. Let variable set $X=\left\{x_{1}, x_{2}, x_{3}, \ldots, x_{n}\right\}$, where $n$ is the number of variables. For a random node variable $x_{i}$, whose range and parent set are $\left\{x_{i}^{1}, x_{i}^{2}, \ldots, x_{i}^{r_{i}}\right\}$ and $\pi_{\mathrm{i}}$, respectively. $\theta_{i j k}=P\left(x_{i}^{k} \mid \pi_{i}^{j}\right)$ represents the possibility that both $x_{i}$ and $\pi_{\mathrm{i}}$ are at the $j$-th possible values. Thus, the probability density of the node in the network is $P\left(\theta \mid D, S^{h}\right)$. Herein, $\theta i j$ is defined as follows.

$$
\theta_{i j}=\left[\theta_{i j 1}, \theta_{i j 2}, \ldots, \theta_{i j r_{i}}\right]\left(i=1,2, \ldots, n ; j=1,2, \ldots, R_{i}\right)
$$

Assuming that (1) the sample data is complete, then (2) the values of $\theta_{i j}$ are, respectively, independent and (3) for every value of $\theta_{i j}$ there is a Dirichlet prior distribution, then the posterior probability distribution can be expressed as follows:

$$
P\left(\theta_{i j} \mid D, S^{h}\right)=\operatorname{Dir}\left(\theta_{i j} \mid \alpha_{i j 1}+N_{i j 1}, \alpha_{i j 2}+N_{i j 2}, \ldots, \alpha_{i j r_{i}}+N_{i j r_{i}}\right)
$$

where $N_{i j k}$ is the sample number in data set $D$, when the $i$-th node is at $k$-th value, meanwhile its parent set is at $j$-th value. 


\subsection{Reasoning Analysisbetween Functional and Structural}

Bayesian Networks have powerful capabilities for dealing with uncertainty reasoning problems, and its network model is an effective tool to express and derivate the uncertainty knowledge. The frequently used derivation algorithms include Junction Tree reasoning, Global Junction Tree reasoning, Belief Propagation reasoning, variable elimination reasoning, and so on [24]. In this study, we employ junction tree reasoning to derivate the network model.

$J T=\langle C, S\rangle$ is defined as the junction tree reasoning algorithm, therein, $C$ represents the clique of the junction tree structure transformed from a Bayesian Network, $S$ is the partition set, which exists in the adjacent cliques $C_{i}$ and $C_{j}$.

Thus, the relation between set $\operatorname{Dom}(C)$ whose corresponding potential function is $\xi_{C}$ and a partition set $\operatorname{Dom}(S)$ whose corresponding potential function is $\xi_{S}$ can be expressed as follows:

$$
P(W)=\xi_{J T}=\frac{\prod_{c \in C} \xi_{c}}{\prod_{s \in S} \xi_{s}}
$$

where $P(W)$ represents the joint probabilities distribution of the variable nodes of the network. $\xi_{J T}$ represents the potential function of the junction tree. Consequently, the potential function of the junction tree represents the joint probabilities distribution.

\section{Case Study}

In order to demonstrate the effectiveness of the proposed Bayesian network model and algorithm for dynamic product structure design, we applied it to the evolution design of electric toothbrushes that were manufactured by a local enterprise. The evolution design rules of the electric toothbrush under the changing market environment are also derived. Figure 4 shows the composition structure of an electric toothbrush model.

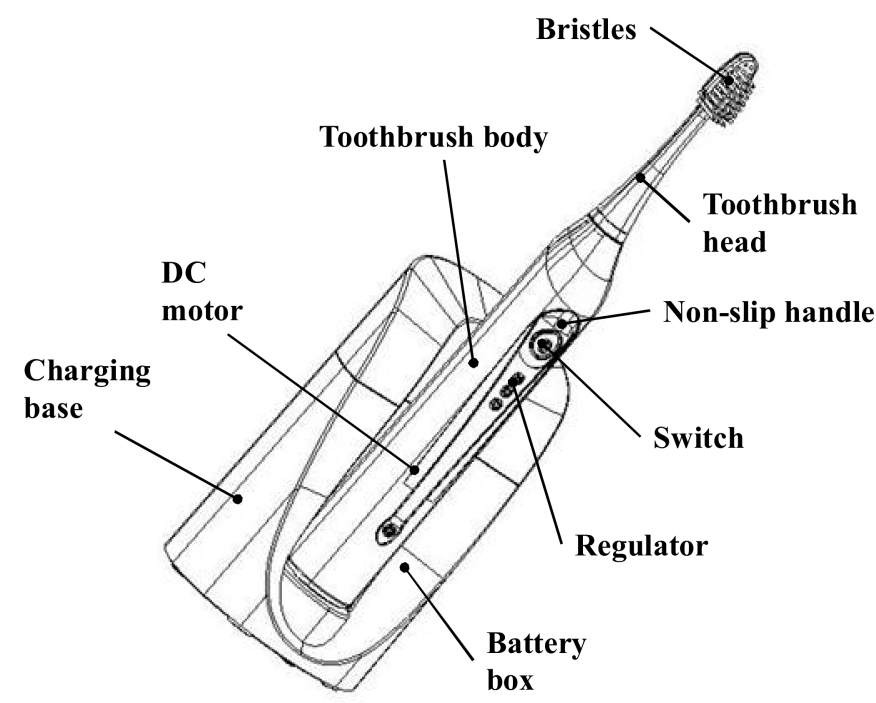

Figure 4. Composition structure of a certain electric toothbrush model.

According to Figure 4, an electric toothbrush is composed of a charging base, DC motor, toothbrush body, bristles, toothbrush head, non-slip handle, switch, regulator, battery box, and other components. The research problem is how to adapt the structure of the product to reflect the market demand and meet the product quality requirements. The design of the electric toothbrush should be carried out with the consideration of customer needs, production costs, structural versatility, manufacturing techniques, and so on. 


\subsection{Evolution Model of Electric Toothbrush Based on Bayesian Network}

Customer needs and the manufacturing process closely relates to the functional structure design of the electric toothbrush. The relationship between customer demand and evolution design is extremely complex. For instance, customers request that the electric toothbrush is equipped with various types of brush heads. On this occasion, the type of the brush head has to be increased based on the direct relationship. However, the manufacturing cost increases by providing more types of the brush heads, which affects the sale price of the product. As the consequence, the customer satisfaction can be negatively influenced based on the indirect relationship.

A large number of the design and sales data for electric toothbrushes are counted, and a family of electric toothbrush products was the focus of analysis, which contains 100 experimental samples and sales data in 23 different regions. In the analysis process, the really important features were captured through statistics and principal component analysis. Therefore, the 26 product parameters in five types of products are selected to establish the analysis model. Consequently, a Bayesian Network based analysis model is needed to reflect the relationship hidden between customer needs and the evolution design of electric toothbrush by using a large amount of historic data.

With the purpose to meet different customer needs, according to the specific design process of electric toothbrushes, the customer needs, toothbrush design elements, and attributes are defined as the network nodes, and their values are listed in Table 1.

Table 1. Nodes and their values in the Bayesian Network.

\begin{tabular}{|c|c|c|c|c|c|c|}
\hline $\begin{array}{l}\text { Brush Head } \\
\text { Type (N1) }\end{array}$ & $\begin{array}{l}\text { Bristle Type } \\
\text { (N2) }\end{array}$ & $\begin{array}{c}\text { Bristle } \\
\text { Quality (N3) }\end{array}$ & $\begin{array}{c}\text { Tongue } \\
\text { Scraper (N4) }\end{array}$ & $\begin{array}{l}\text { Switch Type } \\
\text { (N5) }\end{array}$ & $\begin{array}{l}\text { Power Type } \\
\text { (N6) }\end{array}$ & $\begin{array}{c}\text { Vibration } \\
\text { Frequency } \\
\text { (Once/min) (N7) }\end{array}$ \\
\hline $\begin{array}{c}\text { general:1 } \\
\text { interdental:2 } \\
\text { special effects:3 }\end{array}$ & $\begin{array}{l}\text { hard:1 } \\
\text { soft:2 }\end{array}$ & $\begin{array}{l}\text { poor:1 } \\
\text { medium:2 } \\
\text { good:3 }\end{array}$ & $\begin{array}{c}\text { none:1 } \\
\text { Incidental:2 }\end{array}$ & $\begin{array}{l}\text { weak:1 } \\
\text { strong:2 }\end{array}$ & $\begin{array}{l}\text { dry battery:1 } \\
\text { charger:2 }\end{array}$ & $\begin{array}{c}\text { wide:1 } \\
\text { standard:2 } \\
\text { fixed point:3 }\end{array}$ \\
\hline $\begin{array}{l}\text { Vibration mode } \\
\text { (N8) }\end{array}$ & $\begin{array}{l}\text { Metal shield } \\
\text { (N9) }\end{array}$ & Sleeve (N10) & $\begin{array}{c}\text { Sports } \\
\text { mode (N11) }\end{array}$ & $\begin{array}{l}\text { Brushing } \\
\text { mode (N12) }\end{array}$ & $\begin{array}{l}\text { Timing } \\
\text { function } \\
\text { (N13) }\end{array}$ & Anti-skid (N14) \\
\hline $\begin{array}{c}\text { normal:1 } \\
\text { eccentric: } 2\end{array}$ & $\begin{array}{c}\text { none: } 1 \\
\text { Incidental:2 }\end{array}$ & $\begin{array}{c}\text { none:1 } \\
\text { Incidental:2 }\end{array}$ & $\begin{array}{c}\text { lateral:1 } \\
\text { longitudinal:2 }\end{array}$ & $\begin{array}{l}\text { manual:1 } \\
\text { electric:2 }\end{array}$ & $\begin{array}{c}\text { none:1 } \\
\text { Incidental:2 }\end{array}$ & $\begin{array}{l}\text { no: } 1 \\
\text { yes:2 }\end{array}$ \\
\hline Weight (g)(N15) & $\begin{array}{l}\text { Power cord } \\
\text { length/cm } \\
\text { (N16) }\end{array}$ & $\begin{array}{c}\text { Shape } \\
\text { length/mm } \\
\text { (N17) }\end{array}$ & \begin{tabular}{l}
\multicolumn{1}{c}{ Market } \\
sales/Million \\
pieces (N18)
\end{tabular} & $\begin{array}{l}\text { Cleaning } \\
\text { capacity } \\
\text { (N19) }\end{array}$ & $\begin{array}{l}\text { Customer } \\
\text { satisfaction } \\
\text { (N20) }\end{array}$ & $\begin{array}{c}\text { Service } \\
\text { life/month (N21) }\end{array}$ \\
\hline $\begin{array}{l}\text { Continuous } \\
\text { variable }\end{array}$ & $\begin{array}{l}\text { Continuous } \\
\text { variable }\end{array}$ & $\begin{array}{l}240: 1 \\
250: 2 \\
255: 3 \\
260: 4\end{array}$ & $\begin{array}{l}\text { Continuous } \\
\text { variable }\end{array}$ & $\begin{array}{l}\text { weak:1 } \\
\text { strong:2 }\end{array}$ & $\begin{array}{c}\text { Continuous } \\
\text { variable }(0, \\
1)\end{array}$ & $\begin{array}{l}\text { Continuous } \\
\text { variable }\end{array}$ \\
\hline Duration (N22) & $\begin{array}{l}\text { Convenience } \\
\text { (N23) }\end{array}$ & $\begin{array}{l}\text { Cleaning } \\
\text { time/min } \\
\text { (N24) }\end{array}$ & $\begin{array}{l}\text { Price/yuan } \\
\text { (N25) }\end{array}$ & $\begin{array}{l}\text { Cost/yuan } \\
\text { (N26) }\end{array}$ & - & - \\
\hline $\begin{array}{l}\text { Continuous } \\
\text { variable }\end{array}$ & $\begin{array}{l}\text { inconvenient:1 } \\
\text { convenient:2 } \\
\text { easy:3 }\end{array}$ & $\begin{array}{l}\text { Continuous } \\
\text { variable }\end{array}$ & $\begin{array}{l}\text { Continuous } \\
\text { variable }\end{array}$ & $\begin{array}{l}\text { Continuous } \\
\text { variable }\end{array}$ & - & - \\
\hline
\end{tabular}

Through the above definition of the nodes and attributes, each attribute is corresponding to a node of the network. After that, the network model is trained based on a large number of customer demand and design data collected by collaborating with a local electric toothbrush manufacturer. This model is then modified according to the expertise of the domain experts. The obtained structure of the network model is shown in Figure 5.

The network model contains two kinds of variables, i.e., discrete and continuous. In order to reveal the intrinsic relationship among the continuous variables that have strong correlation, the historical data are analyzed based on the structure of the network model. The joint probability density of the correlation between the nodes of 18, 20, 24, and 25 are shown in Figures 6-9. 
According to Figures 6-9, the largest distribution regions among the continuous variable nodes $18,20,24$, and 25 are revealed. In Figure 6, when the customer satisfaction as well as the market sales are in the ranges of $(0.45,0.52)$ and $(0.9,1.1)$, respectively, then the highest probability is achieved, which implies that the customer satisfaction needs to be improved when the sales is $0.9-1.1$ million/month.

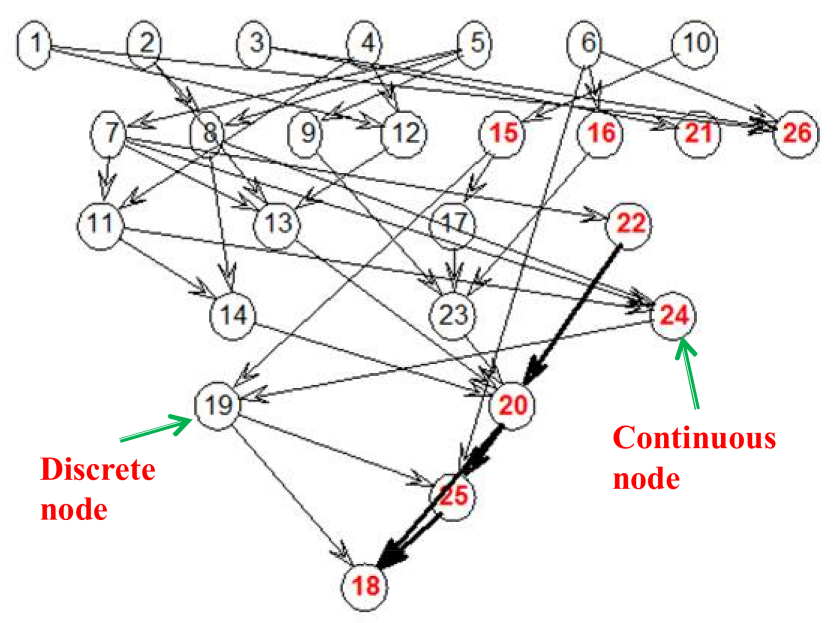

Figure 5. Learned structure of the Bayesian network model.

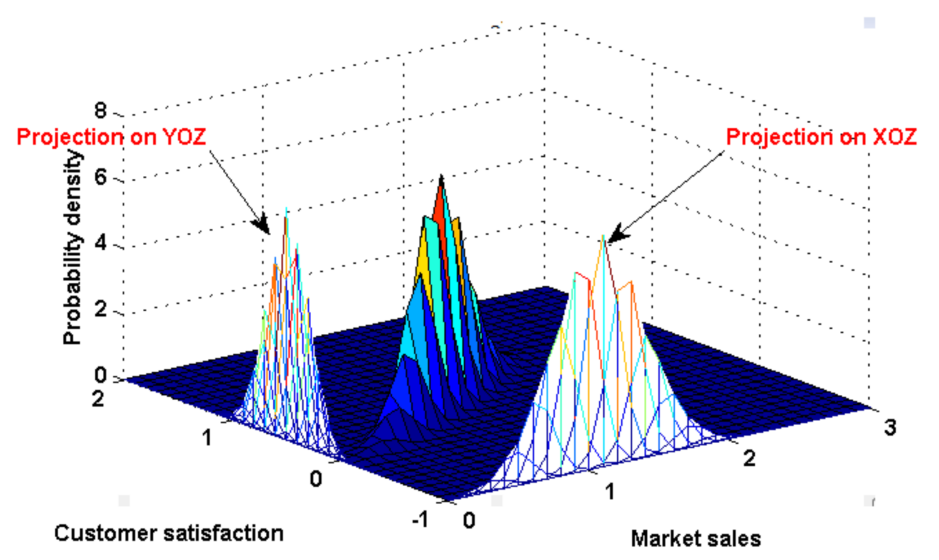

Figure 6. Joint probability densityof customer satisfaction and market sales.

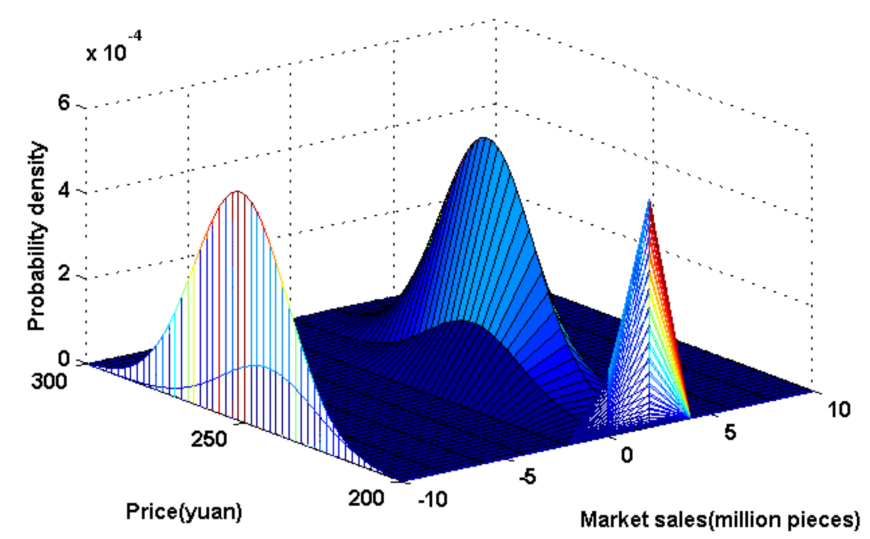

Figure 7. Joint probability densityof price and market sales. 


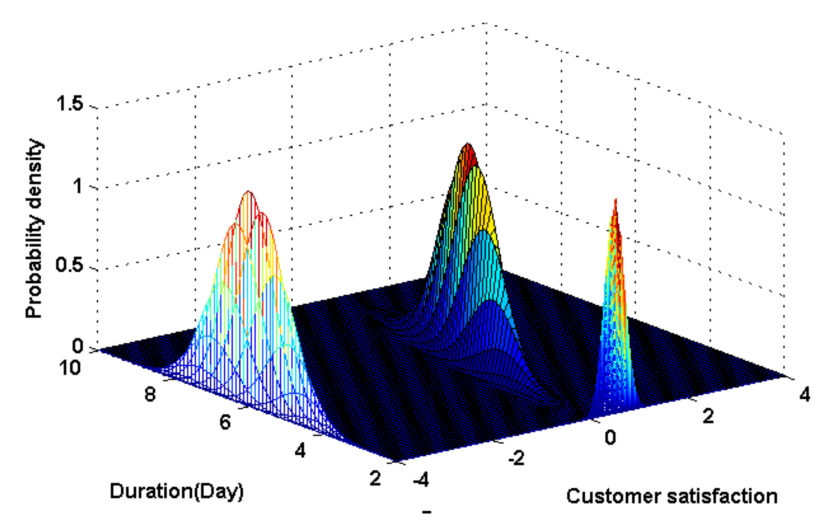

Figure 8. Joint probability densityof customer satisfaction and duration.

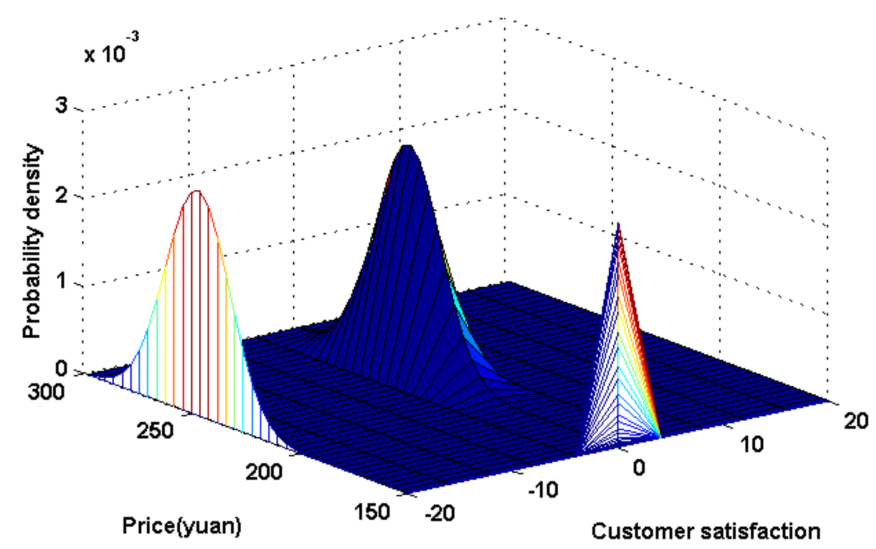

Figure 9. Joint probability densityof price and customer satisfaction.

\subsection{Validation of Evolution Design Rule for Electricaltoothbrushes}

In order to facilitate the network reasoning as well as obtaining accurate results, we conducted discretization of the continuous nodes before the analyzing the joint probability. According to Figures $6-9$, the continuous nodes are divided into two classes, i.e., the second class includes the nodes $15,16,25,26$, while the third class contains nodes 18, 20, 21, 22, and 24 .

Then, we conducted the parameter learning of the network by utilizing the historical data. Then, the reasoning of the evolution design model of the electrical toothbrush is carried out in the absence of any evidence. In addition, conditional probabilities are obtained through two methods: (I) Network is trained (parameter training) using the product design and sales data, and then the conditional probabilities are obtained through network reasoning; (II) the conditional probabilities are determined by field experts. For example, let node $\mathrm{A}$ be conditioned on node $\mathrm{B}$ and $\mathrm{C}$, and the three nodes have two states, respectively. The original probabilities of node A and node B are $(0.4,0.6)$ and $(0.5,0.5)$, respectively, and then the edge distribution probability of node $C$ is $(0.7,0.3)$ after the network model reasoning. However, it was found that the discrepancy between this inferred probabilities $(0.7,0.3)$ and the values in actual situation is too large. So, these two probabilities are revised to $(0.5,0.5)$ by field experts based on their estimation of real cases. We obtained the edge distribution for partial network nodes, which are listed in Table 2. 
Table 2. Edge distribution of part of network nodes.

\begin{tabular}{ccccccc}
\hline \multicolumn{2}{c}{ Node } & N3 & N17 & N20 & N25 & N26 \\
\hline \multirow{4}{*}{ Probability } & $P(X=1)$ & 0.3016 & 0.1686 & 0.3076 & 0.4855 & 0.4513 \\
& $P(X=2)$ & 0.3492 & 0.3087 & 0.3683 & 0.5145 & 0.5487 \\
& $P(X=3)$ & 0.3492 & 0.3373 & 0.3241 & - & - \\
& $P(X=4)$ & - & 0.1854 & - & - & - \\
\hline
\end{tabular}

By reference to Table 1, the result in Table 2 reveals that the customer satisfaction of the three classes of the node N3 are basically the same, i.e., $~ 1 / 3$. Regarding to the node N17, the larger probability (in Table 2, 0.3087 and 0.3373 ) is achieved when the length of the toothbrush is either $250 \mathrm{~cm}$ or $255 \mathrm{~cm}$. As to the nodes N25 and N26, the marginal probability distribution of the product cost is close to that of the sale price, i.e., the ratio of high cost and low cost is nearly the same to the ratio of high sale price and low sale price. Moreover, according to the result, the percentage of low sale price with low cost is about $45 \%$, while the percentage of high sale price with high cost is $55 \%$, implying that the most of the demand is in the level of mid-to-high-end. This is consistent with the fact. On the other hand, in the node N20, the customer satisfaction is mostly in the middle level (0.3683), which shows a potential demand for enhancement. Moreover, the economic nature should also be improved (high cost accounted for 0.5478 on N26). However, high prices accounted for only about 0.5145 on N25, so the latter was significantly lower. Consequently, by training with the historical data, the correctness of the established Bayesian network reasoning model is proved in the absence of evidence.

After above investigation, our evolution analyzing method is further validated under the premise of evidences, by the evolution design process of five types of electrical toothbrushes, as shown in Figure 10.

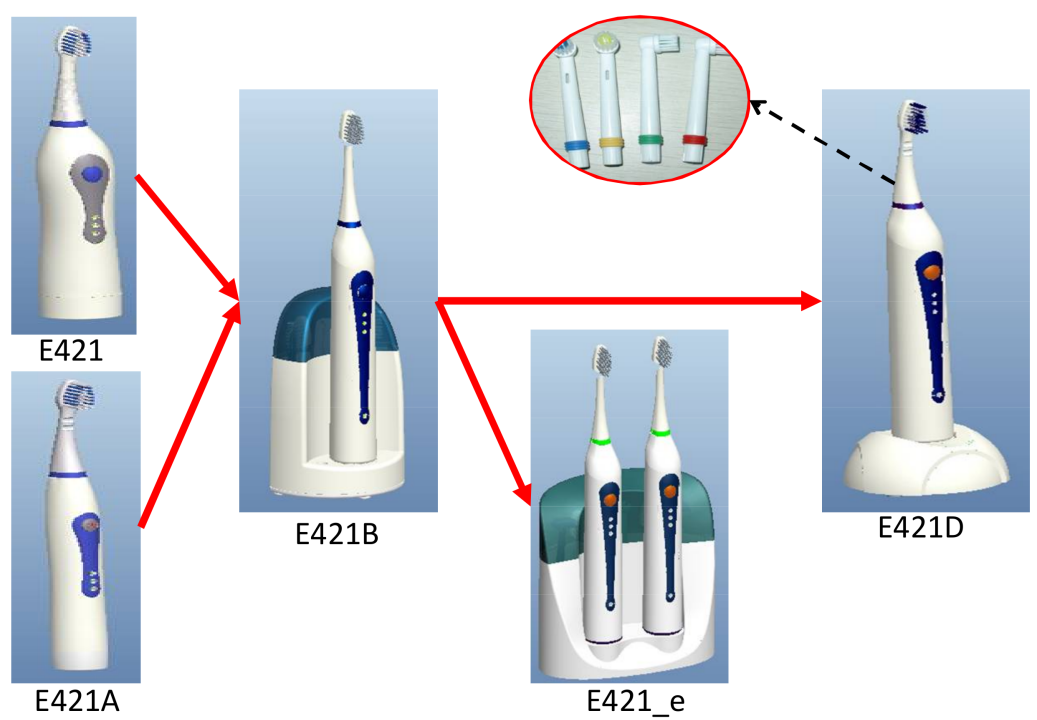

Figure 10. Evolution design process of five types of electrical toothbrushes.

According to Figure 10, the fundamental cause for the evolution of the electric toothbrush can be attributed as the change of customer demand and the progress in science and technology, which therefore results in the variation of the product structure design. On the basis of the research and analysis on the customer demand and enterprise product design, the evolution processes and the driven factors of five types of electric toothbrushes are shown in Table 3. 
Table 3. Evolution parameter of five types of electric toothbrush.

\begin{tabular}{cc}
\hline Evolutionary Process & Customer Needs/Drive Elements \\
\hline $\mathrm{E} 421 \rightarrow \mathrm{E} 421 \mathrm{~B}$ & $\mathrm{~N} 2: 1 \rightarrow 2 ; \mathrm{N} 3: 1 \rightarrow 2 ; \mathrm{N} 6: 1 \rightarrow 2 ; \mathrm{N} 9: 1 \rightarrow 2 ; \mathrm{N} 21:$ lengthen \\
$\mathrm{E} 421 \mathrm{~A} \rightarrow \mathrm{E} 421 \mathrm{~B}$ & $\mathrm{~N} 5: 1 \rightarrow 2 ; \mathrm{N} 6: 1 \rightarrow 2 ; \mathrm{N} 13: 1 \rightarrow 2 ; \mathrm{N} 15:$ lighter; N24: shorter \\
$\mathrm{E} 421 \mathrm{~B} \rightarrow \mathrm{E} 421 \mathrm{~N} 2: 1 \rightarrow 2 ; \mathrm{N} 3: 1 \rightarrow 3 ; \mathrm{N} 10: 1 \rightarrow 2 ; \mathrm{N} 14: 1 \rightarrow 2 ; \mathrm{N} 23: 2 \rightarrow 3$ \\
$\mathrm{E} 421 \mathrm{~B} \rightarrow \mathrm{E} 421 \mathrm{D}$ & $\mathrm{N} 7: 1 \rightarrow 2 ; \mathrm{N} 13: 1 \rightarrow 2 ; \mathrm{N} 19: 1 \rightarrow 2 ; \mathrm{N} 22:$ lengthen; N23:2 $\rightarrow 3 ; \mathrm{N} 24:$ shorter \\
\hline
\end{tabular}

Table 3 illustrates that nodes N7, N13, N19, N22, N23, N24 all have changed in the evolution process from $\mathrm{E} 421 \mathrm{~B}$ to $\mathrm{E} 421 \mathrm{D}$, i.e., both the customer demand and the driver factors have diverged. Indeed, for node N13, the timing function is added. For node N19, the cleaning capacity changes from week to strong. For node N22, the electrical storage capacity is enhanced.

To further illustrate this reasoning process, the E421-D is designed based on three existing products (E421, E421A, E421B) and dynamic customer needs (Reasoning proofs), and this detailed reasoning proofs in this model are as shown in Table 4.

Table 4. Reasoning proofs (three products and customer needs) for E421A design.

\begin{tabular}{cccccccc}
\hline Proofs & N1 & N2 & N3 & N4 & N5 & N6 & N7 \\
\hline E421 & 2 & 1 & 1 & 1 & 2 & 1 & 3 \\
E420A & 2 & 1 & 2 & 1 & 1 & 1 & 2 \\
E421B & 3 & 2 & 3 & 2 & 1 & 2 & 1 \\
Demands & - & - & - & - & 1 & 2 & 2 \\
\hline Proofs & N8 & N9 & N10 & N11 & N12 & N13 & N14 \\
\hline E421 & 1 & 1 & 1 & 1 & 1 & 1 & 1 \\
E420A & 1 & 1 & 1 & 1 & 1 & 1 & 1 \\
E421B & 1 & 2 & 2 & 2 & 2 & 1 & 2 \\
Demands & - & - & - & - & 2 & 2 & - \\
\hline Proofs & N15 & N16 & N17 & N18 & N19 & N20 & N21 \\
\hline E421 & 2 & 1 & 4 & 1 & 1 & 2 & 1 \\
E420A & 1 & 2 & 3 & 2 & 1 & 2 & 1 \\
E421B & 1 & 2 & 1 & 3 & 1 & 3 & 2 \\
Demands & - & - & - & - & 2 & 3 & 3 \\
\hline Proofs & N22 & N23 & N24 & N25 & N26 & & \\
\hline E421 & 1 & 1 & 1 & 2 & 2 & - & - \\
E420A & 1 & 2 & 2 & 1 & 1 & - & - \\
E421B & 1 & 2 & 2 & 2 & 2 & - & - \\
Demands & 2 & 3 & 3 & - & - & - & - \\
\hline
\end{tabular}

Where, the network node N5, N6, N7, N12, N13, N19, N20, N21, N22, N23, and N24 are the direct proofs of customer demands. Therefore, the design parameters of product E421D are obtained by model reasoning, which is shown as Table 5 .

Taking the customer demand/driver factors in the evolution process shown in Table 1 as the proof, we identified the nodes that have large changing probabilities in the network reasoning model by using the joint tree reasoning algorithm. The results are shown in Table 6 .

According to Table 6, when E421 is driven by the needs of nodes N2, N3, N9, N21 (shown in Table 3), $P(X=2)$ in nodes $\mathrm{N} 12$ and N18 have greater probability of occurrence. That is to say, the potential need that the brushing mode changes from manual to electrical is stronger. In this scenario, the market sales would improve although the other conditions are the same. This is in agreement with the evolution design process from model E421 to E421B. Regarding to the other three models, i.e., E421A to E421B, E421B to E421e, E421B to E421D, the explanation of the evolution processes is similar. Consequently, the above evolution processes demonstrated the validity and effectiveness of 
the established analyzing network model for electrical toothbrush evolution. The detailed explanation of the evolution process is listed in Table 7.

Table 5. Reasoning results in E421A design.

\begin{tabular}{cccccccc}
\hline Design Data & $\mathbf{N 1}$ & $\mathbf{N 2}$ & $\mathbf{N 3}$ & $\mathbf{N 4}$ & $\mathbf{N 5}$ & $\mathbf{N 6}$ & $\mathbf{N 7}$ \\
\hline$P(X=1)$ & 0.1781 & 0.2123 & 0.3612 & 0.4375 & $\mathbf{1}$ & 0 & 0 \\
$P(X=2)$ & 0.3215 & $\mathbf{0 . 7 8 7 7}$ & 0.1474 & $\mathbf{0 . 5 6 2 5}$ & 0 & $\mathbf{1}$ & $\mathbf{1}$ \\
$P(X=3)$ & $\mathbf{0 . 5 0 0 4}$ & - & $\mathbf{0 . 4 9 1 4}$ & - & - & - & 0 \\
$P(X=4)$ & - & - & - & - & - & - & - \\
E421D & 3 & 2 & 3 & 2 & 1 & 2 & 2 \\
\hline Design data & $\mathbf{N 8}$ & $\mathbf{N 9}$ & $\mathbf{N 1 0}$ & $\mathbf{N 1 1}$ & $\mathbf{N 1 2}$ & $\mathbf{N 1 3}$ & $\mathbf{N 1 4}$ \\
\hline$P(X=1)$ & 0.2062 & 0.4231 & 0.3326 & 0.2378 & 0 & 0 & 0.4721 \\
$P(X=2)$ & $\mathbf{0 . 7 9 3 8}$ & $\mathbf{0 . 5 7 6 9}$ & $\mathbf{0 . 6 6 7 4}$ & $\mathbf{0 . 7 6 2 2}$ & 1 & 1 & $\mathbf{0 . 5 2 7 9}$ \\
$P(X=3)$ & - & - & - & - & - & - & - \\
$P(X=4)$ & - & - & - & - & - & - & - \\
E421D & 2 & 2 & 2 & 2 & 2 & 2 & 2 \\
\hline Design data & $\mathbf{N 1 5}$ & $\mathbf{N 1 6}$ & $\mathbf{N 1 7}$ & $\mathbf{N 1 8}$ & $\mathbf{N 1 9}$ & $\mathbf{N 2 0}$ & $\mathbf{N 2 1}$ \\
\hline$P(X=1)$ & $\mathbf{1}$ & 0.4067 & $\mathbf{0 . 5 0 4 6}$ & 0.246 & 0 & 0 & 0 \\
$P(X=2)$ & 0 & $\mathbf{0 . 5 9 3 3}$ & 0.1585 & 0.2245 & $\mathbf{1}$ & 0 & 0 \\
$P(X=3)$ & - & - & 0.2783 & $\mathbf{0 . 5 2 9 5}$ & - & $\mathbf{1}$ & $\mathbf{1}$ \\
$P(X=4)$ & - & - & 0.0586 & - & - & - & - \\
E421D & 1 & 2 & 1 & 3 & 2 & 3 & 3 \\
\hline Design data & $\mathbf{N 2 2}$ & $\mathbf{N 2 3}$ & $\mathbf{N 2 4}$ & $\mathbf{N 2 5}$ & $\mathbf{N 2 6}$ & & - \\
\hline$P(X=1)$ & 0 & 0 & 0 & 0.3128 & 0.2594 & - & - \\
$P(X=2)$ & $\mathbf{1}$ & 0 & 0 & $\mathbf{0 . 6 8 7 2}$ & $\mathbf{0 . 7 4 0 6}$ & - & - \\
$P(X=3)$ & 0 & $\mathbf{1}$ & - & - & - & - & - \\
$P(X=4)$ & - & 3 & 3 & 2 & 2 & - & - \\
E421D & 2 & & - & & & &
\end{tabular}

Table 6. Nodes with large changing probability.

\begin{tabular}{cccccc}
\hline Evolutionary Process & Node & $\boldsymbol{P}(\boldsymbol{X}=\mathbf{1})$ & $\boldsymbol{P}(\boldsymbol{X}=\mathbf{2})$ & $\boldsymbol{P}(\boldsymbol{X}=\mathbf{3})$ & $\boldsymbol{P}(\boldsymbol{X}=\mathbf{4})$ \\
\hline \multirow{2}{*}{$\mathrm{E} 421 \rightarrow \mathrm{E} 421 \mathrm{~B}$} & $\mathrm{~N} 12$ & 0.3205 & 0.6795 & - & - \\
& $\mathrm{N} 18$ & 0.2851 & 0.5204 & 0.1945 & - \\
\hline \multirow{2}{*}{$\mathrm{E} 421 \mathrm{~A} \rightarrow \mathrm{E} 421 \mathrm{~B}$} & $\mathrm{~N} 11$ & 0.203 & 0.797 & - & - \\
& $\mathrm{N} 12$ & 0.336 & 0.664 & - & - \\
& $\mathrm{N} 17$ & 0.2219 & 0.5313 & 0.0221 & 0.2247 \\
\hline \multirow{2}{*}{$\mathrm{E} 421 \mathrm{~B} \rightarrow \mathrm{E} 421 \mathrm{e}$} & $\mathrm{N} 8$ & 0.2051 & 0.7949 & - & - \\
& $\mathrm{N} 15$ & 0.6338 & 0.3662 & - & - \\
& $\mathrm{N} 4$ & 0.4375 & 0.5625 & - & - \\
& $\mathrm{N} 8$ & 0.2062 & 0.7938 & - & - \\
$\mathrm{E} 421 \mathrm{~B} \rightarrow \mathrm{E} 421 \mathrm{D}$ & $\mathrm{N} 11$ & 0.2378 & 0.7622 & - & - \\
& $\mathrm{N} 16$ & 0.4067 & 0.5933 & - & 0.0586 \\
& $\mathrm{~N} 17$ & 0.5046 & 0.1585 & 0.2783 & - \\
\hline
\end{tabular}

Table 7. Evolution design process of four kinds of electric toothbrushes.

\begin{tabular}{ccc}
\hline Evolutionary Process & Drive Elements & Adaptive Design \\
\hline $\mathrm{E} 421 \rightarrow \mathrm{E} 421 \mathrm{~B}$ & $\mathrm{~N} 2: 1 \rightarrow 2 ; \mathrm{N} 3: 1 \rightarrow 2 ; \mathrm{N} 6: 1 \rightarrow 2 ; \mathrm{N} 9: 1 \rightarrow 2 ; \mathrm{N} 21:$ lengthen & $\mathrm{N} 12: 1 \rightarrow 2 ; \mathrm{N} 18:$ larger \\
$\mathrm{E} 421 \mathrm{~A} \rightarrow \mathrm{E} 421 \mathrm{~B}$ & $\mathrm{~N} 5: 1 \rightarrow 2 ; \mathrm{N} 6: 1 \rightarrow 2 ; \mathrm{N} 13: 1 \rightarrow 2 ; \mathrm{N} 15:$ lighter; N24: shorter & $\mathrm{N} 11: 1 \rightarrow 2 ; \mathrm{N} 12: 1 \rightarrow 2 ; \mathrm{N} 17: 3 \rightarrow 2$ \\
$\mathrm{E} 421 \mathrm{~B} \rightarrow \mathrm{E} 421 \mathrm{e}$ & $\mathrm{N} 2: 1 \rightarrow 2 ; \mathrm{N} 3: 1 \rightarrow 3 ; \mathrm{N} 10: 1 \rightarrow 2 ; \mathrm{N} 14: 1 \rightarrow 2 ; \mathrm{N} 23: 2 \rightarrow 3$ & $\mathrm{~N} 8: 1 \rightarrow 2 ; \mathrm{N} 10: 2 \rightarrow 1 ; \mathrm{N} 15: 1 \rightarrow 2$ \\
$\mathrm{E} 421 \mathrm{~B} \rightarrow \mathrm{E} 421 \mathrm{D}$ & $\mathrm{N} 7: 1 \rightarrow 2 ; \mathrm{N} 13: 1 \rightarrow 2 ; \mathrm{N} 19: 1 \rightarrow 2 ; \mathrm{N} 22:$ lengthen; & $\mathrm{N} 4: 1 \rightarrow 2 ; \mathrm{N} 8: 1 \rightarrow 2 ; \mathrm{N} 11: 1 \rightarrow 2 ; \mathrm{N} 16:$ \\
& $\mathrm{N} 23: 2 \rightarrow 3 ; \mathrm{N} 24:$ shorter & lengthen; $\mathrm{N} 17: 2 \rightarrow 1 ; \mathrm{N} 18:$ larger \\
\hline
\end{tabular}


In the derivation model, different customers' demands can be used as evidence to infer from the network, and the result would propose reasonable change (probability) of the function or the design, therefore providing the theoretical guidance to the designer in product design process.

Based on the analysis of the evolution rules of the electric toothbrush, we analyzed several non-design indexes nodes, such as market sales N18, customer satisfaction N20, sale price N25, and product cost $\mathrm{N} 26$. The comparison of the maximum probability of the above four factors are shown in Figure 11.

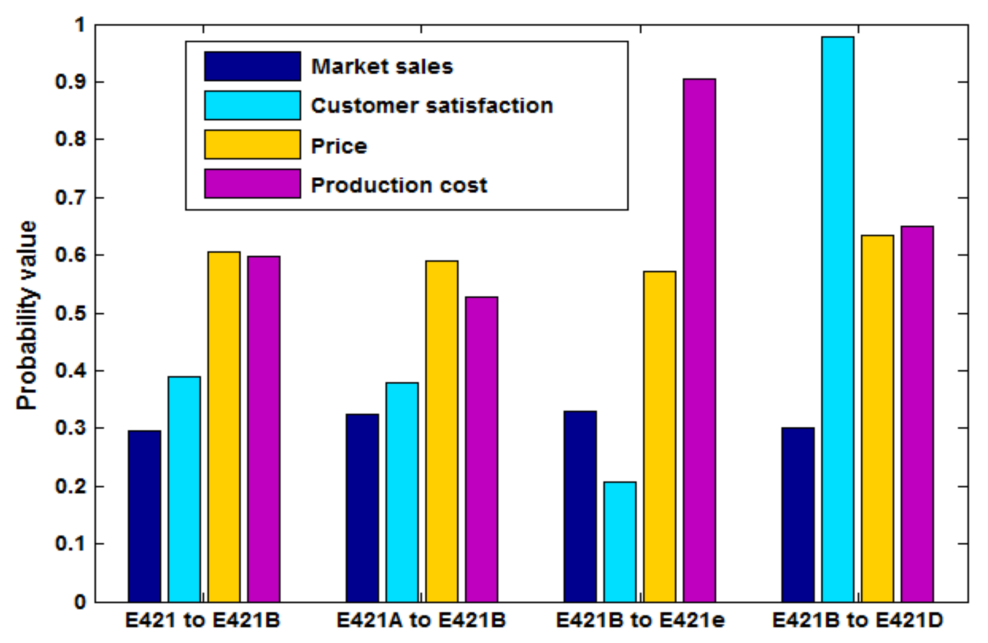

Figure 11. Maximum probability comparison of four evolution process indicators.

According to Figure 11, in the evolution process from E421B to E421D, the customer satisfaction reaches maximum, i.e., $P(X=3)=0.9772$. However, the sale price is also at its maximum. Therefore, there is no obvious advantage in market sales. This is in agreement with the objective reality that type E421D is the most popular electric toothbrush in the market, which proves the correctness of the dynamic design evolution model.

In the evolution process from model E421B to model E421E, the product is eliminated due to its minimum sales and customer satisfaction, but highest cost. The evolution processes from E421, E421A, to $\mathrm{E} 421 \mathrm{~B}$ are similar to the above: the power supply for the electrical toothbrush is changed from dry cell to charging, which increases the product cost and therefore results in the increase of the sale price $(P(X=2)=0.5974)$, thus the customer satisfaction is moderate. The above indexes are non-design factors in the evolution process of electrical toothbrushes, which can effectively reduce the cost in the evolution process from model E421B to model E421D, therefore promoting the sale amount and achieving the goal of maximizing the overall performance of the enterprise. The above reasoning on the factors relating market demand, product design, and costs are all in agreement with actual reality, which verified the correctness and validity of the dynamic identification model.

\section{Conclusions}

Utilizing the availability of data accumulated through the implementation process in product evolution, we propose a dynamic product design evolution analysis model that is based on the Bayesian network for reasoning on product function evolution. It enables us to reason about the relationships of all the related factors from customer demand to product sales by handling the market demand uncertainty and product structure diversity based on probabilistic reasoning.

Driven by varying customer needs, product structure design needs to be constantly updated in product evolution. This study analyzed the dynamic indicator data about customer demand, product functions and structures. We have identified how customer demands of the product and structural 
design and dynamic design schemes are influenced by each other using a quantitative reasoning approach that is based on the learned Bayesian Network.

As a case study, we applied the proposed dynamic analysis model to analyze the evolutionary design of electric toothbrushes. The effectiveness and applicable value of the method are validated, which brings several benefits for the manufacturer. First, the designers can better understand and use product evolution design rules. Second, the enterprise performance can be maximized guided by the data-driven product evolution model and new design ideas may be generated by interrogating with the Bayesian network model to achieve a dynamic product design.

This paper proposes a product evolution design analysis model that is still more qualitative in terms of the reasoning results since it is a discrete Bayesian model. However, product dynamic design is strongly related to complex factors, such as customer demands, enterprise resources, and other related factors. It is thus interesting to explore how to establish a more objective and precise model to describe all of the factors in product evolution design. In addition, in order to highlight the time characteristic, Dynamic Bayesian model is the focus of our next study in product evolution design.

Acknowledgments: This work is supported by the National Natural Science Foundation of China under Grant Nos. 51505094, 51475097 and 51741101, and Science and Technology Foundation of Guizhou Province under Grant Nos. JZ [2014]2001, [2016]1037, [2017]2029, Talents [2015]4011 and [2016]5013, Collaborative Innovation [2015]02.

Author Contributions: S.L. and Y.W. conceived of and designed the study. S.L., Y.X., and J.J.H. worked on the algorithm design. Y.W. and Y.X. did the experiments. Y.W., Y.X. and J.J.H. analyzed the data. S.L., Y.W., Y.X. and J.J.H. wrote the manuscript. J.H. and J.J.H. revised and polished the manuscript. All authors have read and approved the final manuscript.

Conflicts of Interest: The authors declare no conflict of interest.

\section{References}

1. Hu, G.Z.; Xu, X.J.; Xiao, S.N.; Yang, G.W.; Pu, F. Product data model for performance-driven design. Chin. J. Mech. Eng. 2017, 30, 1112-1122. [CrossRef]

2. Ma, J.; Kim, H.M. Product family architecture design with predictive, data-driven product family design method. Res. Eng. Des. 2015, 27, 1-17. [CrossRef]

3. Chien, C.F.; Kerh, R.; Lin, K.Y.; Yu, P.I. Data-driven innovation to capture user-experience product design: An empirical study for notebook visual aesthetics design. Comput. Ind. Eng. 2016, 99, 162-173. [CrossRef]

4. Blessing, L.T.M.; Chakrabarti, A. DRM, a Design Research Methodology; Springer: London, UK, 2009.

5. Ravasi, D.; Stigliani, I. Product design: A review and research agenda for management studies. Int. J. Manag. Rev. 2012, 14, 464-488. [CrossRef]

6. Kulatunga, A.K.; Karunatilake, N.; Weerasinghe, N.; Ihalawatta, R.K. Sustainable manufacturing based decision support model for product design and development process. Procedia CIRP 2015, 26, 87-92. [CrossRef]

7. Rezapour, S.; Hassani, A.; Farahani, R.Z. Concurrent design of product family and supply chain network considering quality and price. Transp. Res. Part E Logist. Transp. Rev. 2015, 81, 18-35. [CrossRef]

8. Baud-Lavigne, B.; Agard, B.; Penz, B. Simultaneous product family and supply chain design: An optimization approach. Int. J. Prod. Econ. 2016, 174, 111-118. [CrossRef]

9. Algeddawy, T.; Elmaraghy, H. Reactive design methodology for product family platforms, modularity and parts integration. CIRP J. Manuf. Sci. Technol. 2013, 6, 34-43. [CrossRef]

10. Giovannini, A.; Aubry, A.; Panetto, H.; Haouzi, H.E.; Junior, O.C.; Pierrel, L. Knowledge representation, retrieval and reuse for product family design: An anti-logicist approach. Comput. Ind. Eng. 2016, 101, 391-402. [CrossRef]

11. Agard, B.; Penz, B. A simulated annealing method based on a clustering approach to determine bills of materials for a large product family. Int. J. Prod. Econ. 2009, 117, 389-401. [CrossRef]

12. Jiao, J.R.; Simpson, T.W.; Siddique, Z. Product family design and platform-based product development: A state-of-the-art review. J. Intell. Manuf. 2007, 18, 5-29. [CrossRef]

13. Zhang, M.; Zhao, X.; Qi, Y. The effects of organizational flatness, coordination, and product modularity on mass customization capability. Int. J. Prod. Econ. 2014, 158, 145-155. [CrossRef] 
14. Guthrie, R. Program design, coding, and testing. Encycl. Inf. Syst. 2003, 3, 529-543.

15. Alsawalqah, H.I.; Kang, S.; Lee, J. A method to optimize the scope of a software product platform based on end-user features. J. Syst. Softw. 2014, 98, 79-106. [CrossRef]

16. Schuh, G.; Rudolf, S.; Vogels, T. Performance measurement of modular product platforms. Procedia CIRP 2014, 17, 266-271. [CrossRef]

17. Wiltschnig, S.; Bo, T.C.; Ball, L.J. Collaborative problem-solution co-evolution in creative design. Des. Stud. 2013, 34, 515-542. [CrossRef]

18. Bryan, A.; Ko, J.; Hu, S.J.; Koren, Y. Co-evolution of product families and assembly systems. CIRP Ann. Manuf. Technol. 2008, 56, 41-44. [CrossRef]

19. Smith, S.; Smith, G.; Shen, Y.T. Redesign for product innovation. Des. Stud. 2012, 33, 160-184. [CrossRef]

20. Negendahl, K. Building performance simulation in the early design stage: An introduction to integrated dynamic models. Autom. Constr. 2015, 54, 39-53. [CrossRef]

21. Gries, M. Methods for evaluating and covering the design space during early design development. Integr. VLSI J. 2004, 38, 131-183. [CrossRef]

22. Hou, L.; Wang, H.L.; Liu, Y.Y. Research on product platform innovation and evolution based on lifecycle. Key Eng. Mater. 2010, 431, 82-85. [CrossRef]

23. Meyer, M.H.; Tertzakian, P.; Utterback, J.M. Metrics for managing research and development in the context of the product family. Manag. Sci. 1997, 43, 88-111. [CrossRef]

24. Wang, H.L.; Hou, L.; Li, M.; Wang, S.F. Research on the product platform life cycle and its management strategies. Appl. Mech. Mater. 2010, 37, 1105-1109. [CrossRef]

25. Eisenbart, B.; Gericke, K.; Blessing, L.T.M.; Mcaloone, T.C. A dsm-based framework for integrated function modelling: Concept, application and evaluation. Res. Eng. Des. 2017, 28, 25-51. [CrossRef]

26. Ramsaier, M.; Holder, K.; Zech, A.; Stetter, R.; Rudolph, S.; Till, M. Digital Representation of Product Functions in Multicopter Design. In Proceedings of the 21st International Conference on Engineering Design (ICED 17) Vol. 1: Resource Sensitive Design, Design Research Applications and Case Studies, Vancouver, BC, Canada, 21-25 August 2017.

27. Tucker, C.S.; Kim, H.M. Data-driven decision tree classification for product portfolio design optimization. J. Comput. Inf. Sci. Eng. 2009, 9, 790-792. [CrossRef]

28. Hosseini, S.; Barker, K. Modeling infrastructure resilience using bayesian networks: A case study of inland waterway ports. Comput. Ind. Eng. 2016, 93, 252-266. [CrossRef]

29. Hosseini, S.; Khaled, A.A.; Sarder, M.D. A general framework for assessing system resilience using bayesian networks: A case study of sulfuric acid manufacturer. J. Manuf. Syst. 2016, 41, 211-227. [CrossRef]

30. Hosseini, S.; Barker, K. A bayesian network model for resilience-based supplier selection. Int. J. Prod. Econ. 2016, 180, 68-87. [CrossRef]

31. Pearl, J. Fusion, propagation, and structuring in belief networks. Artif. Intell. 1986, 29, 241-288. [CrossRef]

32. Garbolino, P.; Taroni, F. Evaluation of scientific evidence using bayesian networks. Forensic Sci. Int. 2002, 125, 149-155. [CrossRef]

(C) 2018 by the authors. Licensee MDPI, Basel, Switzerland. This article is an open access article distributed under the terms and conditions of the Creative Commons Attribution (CC BY) license (http://creativecommons.org/licenses/by/4.0/). 